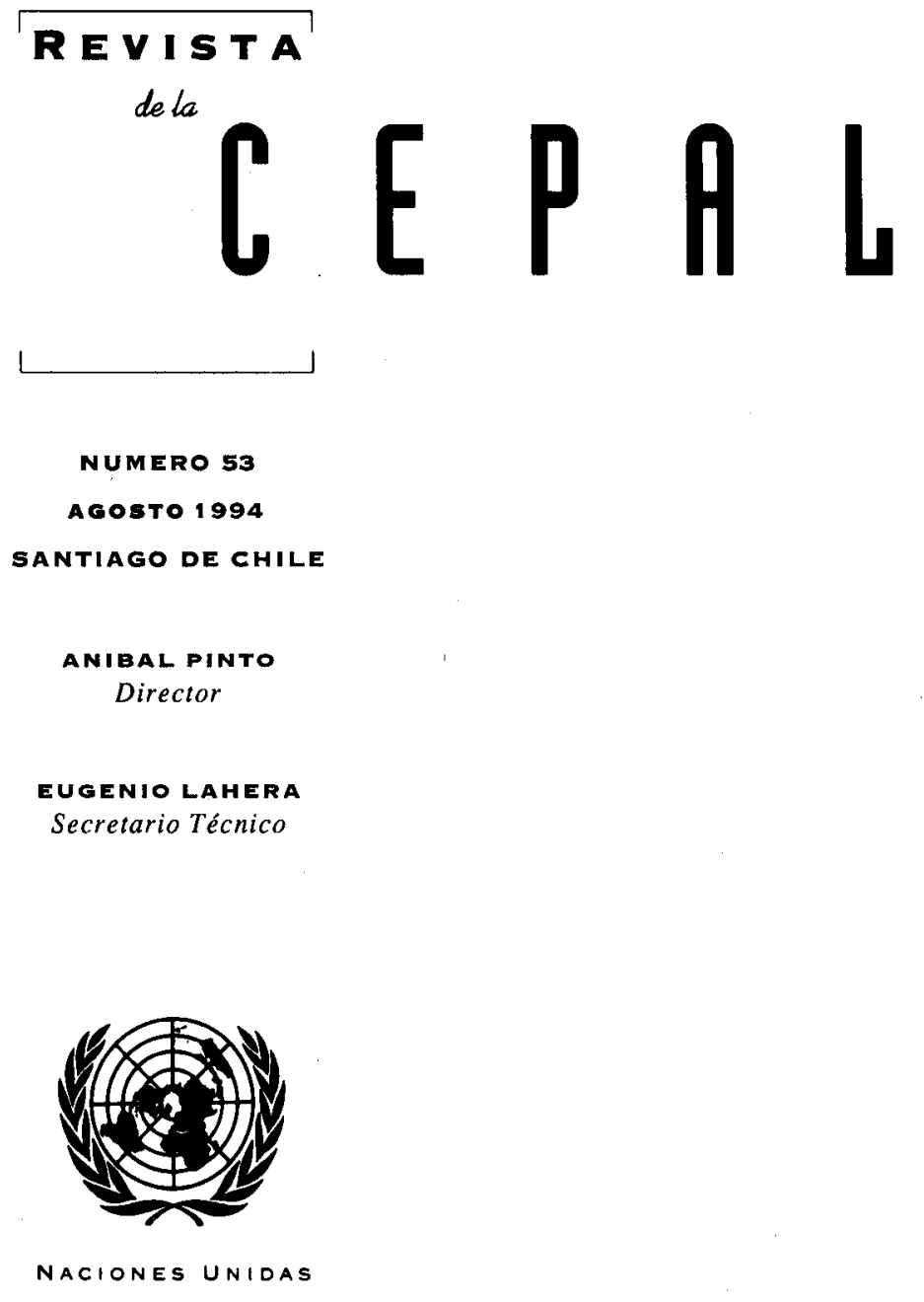


América Latina y el Caribe frente a la economía mundial

Gert Rosenthal

Afluencia de capitales externos y políticas macroeconómicas

Andras Uthoff y Daniel Titelman

Represión fínanciera y patrón de financiamlento latínoamericano

31

Marcos Antonio Macedo Cintra

Políticas de competitividad

49

Wilson Peres

Política industrial y fomento de la competitividad

Osvaldo Rosales

El regionalismo abierto y la integración económica

Juan A. Fuentes $K$.

Transformaciones del trabajo femenino urbano

91

Irma Arriagada

La gestión del agua y las cuencas en América Latina

Axel Dourojeanni

Políticas públicas y competitividad de las exportaciones

agrícolas

Milton von Hesse

Agroindustria y transformación productiva de la pequeña agricultura

Alejandro Schejtman

Grupos privados nacionales en México, 1988-1993

Celso Garrido

Evolución y perspectivas de la reforma y la apertura en China 


\section{Políticas públicas y competitividad de las exportaciones agrícolas}

\section{Milton Von Hesse}

Economista y

Consultor de la

Unidad de Desarrollo

Agrícola de la CEPAL.
Este artículo evalúa el comportamiento de las exportaciones agrícolas de la región en el período posterior al desencadenamiento de la crisis de la deuda y hace algunas recomendaciones respecto a la acción del sector público con miras a mejorar su competitividad. En la sección I se describen las principales tendencias que han ido configurando los mercados agrícolas internacionales en las últimas décadas, y que han marcado sus tendencias futuras. En la sección II se muestra cómo ha reaccionado la oferta agrícola regional ante dichos cambios. En la sección III, a partir de una estilización del comportamiento de los productos agrícolas en los mercados internacionales, se establecen ciertos criterios para el diseño de políticas que tiendan a favorecer el desarrollo de estrategias competitivas de mediano y largo plazo para la oferta agrícola exportable, sobre todo para facilitar la incorporación de los sectores agrícolas menos capitalizados (pequeños y medianos productores) a los beneficios de la estrategia de desarrollo orientada hacia la integración con el mundo. La tesis implícita en el análisis en lo que se refiere a la intervención pública es que si bien el ajuste y la apertura han logrado avances hacia la estabilidad macroeconómica y algún dinamismo exportador, aún subsisten imperfecciones en los mercados internos —debidas más bien a factores microeconómicos- que dificultan la incorporación de los productores de menores ingresos a los beneficios de la agricultura de exportación. 


\section{La configuración de los mercados agrícolas}

\section{internacionales}

Entender el funcionamiento de los mercados agrícolas internacionales a partir de las tendencias de los principales factores que lo han ido configurando será de mucha utilidad para evaluar, en las secciones posteriores, el comportamiento competitivo de la oferta de exportación agrícola latinoamericana (especialmente en el período posterior a las reformas) y examinar la participación del sector público en el diseño de una estrategia competitiva de mediano y largo plazo que permita enfrentar los mercados internacionales de manera más eficiente.

\section{El impacto del desarrollo económico y de las transformaciones de los hogares en los hábi- tos de consumo alimenticio}

Desde que finalizó la segunda guerra mundial, los países de altos ingresos han experimentado un crecimiento económico que ha ido acompañado de importantes transformaciones en la composición de los hogares y que, por lo tanto, ha incidido en las formas de vida de éstos. En los países de la Organización de Cooperación y Desarrollo Económicos (OCDE), que representan alrededor del $75 \%$ de los mercados de destino de las exportaciones agrícolas latinoamericanas, en el período de posguerra se ha incrementado sostenidamente el ingreso per cápita, ${ }^{1}$ ha disminuido el número de personas en los hogares ${ }^{2} \mathrm{y}$ ha

$\square \quad$ El autor está en deuda con Emiliano Ortega y Geraldo Müller, con quienes mantuvo discusiones en distintas etapas de la realización del presente artículo. También agradece los comentarios y sugerencias de Martine Dirven y Rinske Warner, de la Unidad de Desarrollo Agrícola de la CEPAL y de los editores de la Revista. Los errores, omisiones y/o malas interpretaciones son de la exclusiva responsabilidad del autor.

1 Según cifras del Banco Mundial, el producto nacional bruto per cápita en los países de altos ingresos -expresado en dólares constantes de 1990- aumentó de 10828 a 19590 dólares entre 1965 y 1990; es decir, casi se duplicó en el período. En la actualidad, la cifra per cápita de esos países equivale a 9 veces la de los países de América Latina y el Caribe (Banco Mundial, 1992).

2 Entre principios de los años sesenta y principios de los ochenta el porcentaje de hogares grandes dentro del total de hogares se redujo en países como Alemania (del 14 al 8\%), Suecia (del 13 al $6 \%$ ), Francia (del 20 al $15 \%$ ) y Holanda (del 27 al $13 \%$ ), mientras que aumentó la proporción de hogares constituidos por una sola persona (Schwartz, 1988) habido una creciente incorporación de la mujer al mercado laboral. ${ }^{3}$

Estas tres características asociadas al desarrollo económico han tenido repercusiones directas o indirectas sobre los hábitos de consumo alimenticios $\mathrm{y}$, por lo tanto, han influido también en la demanda de productos agrícolas. Un primer efecto que se desea resaltar es la observación empírica de que a medida que el ingreso de los individuos aumenta, la proporción de los alimentos en la composición del gasto va perdiendo importancia relativa, aunque en términos absolutos el gasto pueda estar aumentando (fenómeno conocido como Ley de Engel en la literatura económica). Asociada a esta disminución de la proporción del gasto en alimentos, se da una mejora cualitativa de la dieta del poblador con mayores ingresos, ya que, en general, conforme aumenta el ingreso, aumentan también las preocupaciones por una adecuada nutrición y una buena salud.

El incremento de las remuneraciones reales permite utilizar el tiempo libre en actividades que no tienen que ver con el trabajo diario. Los viajes que se realizan durante los períodos de vacaciones llevan a tomar contacto con nuevas variedades de alimentos (principalmente frutas y hortalizas consideradas exóticas por los habitantes del hemisferio norte), las que al retorno son demandadas por los vacacionistas en sus lugares de origen. Los deportes que se practican en los momentos libres también han contribuido a mejorar la dieta de las personas de altos ingresos, al asociarse a su práctica el consumo de productos saludables y de bajo contenido graso (generalmente frutas $\mathrm{y}$ hortalizas).

Las mejorías de los ingresos aunadas a la tendencia a formar hogares con bajo número de personas y a la mayor incorporación de las mujeres a labores económicas fuera del hogar, han conferido al consumo de alimentos en las naciones industrializadas dos

\footnotetext{
3 Así, por ejemplo, en los Estados Unidos 1a participación de las mujeres en la fuerza laboral ha venido aumentando desde un $32 \%$ en 1947 , a un $39 \%$ en 1965 y al $51 \%$ a principios de los años ochenta (Bustillo y Barret, 1993).
} 
características adicionales. La primera es la mayor importancia del gasto en alimentos fuera de casa, y la segunda el deseo de consumir alimentos de alta calidad, pero que a la vez sean de fácil y rápida preparación.

Estos cambios de conducta observados en los consumidores de los países más industrializados han derivado en que el consumo de alimentos en los principales mercados de destino de las exportaciones agrícolas de América Latina presente las siguientes tendencias: ${ }^{4}$ i) Sustitución de productos frescos por productos preparados (sopas deshidratadas, puré instantáneo, platos congelados, platos precocidos, jugos y zumos de fruta, etc.); ii) aumento del consumo de frutas tropicales y hortalizas de contraépoca en estado fresco; iii) incremento de la demanda de productos alimenticios que corresponden a una porción (entre 250 y 300 gr). De ahí que en el caso específico de las frutas, las de alto peso unitario -como las piñas- se consuman preferentemente en períodos festivos, cuando se reciben invitados en casa; iv) reducción del consumo de azúcar; v) reducción del consumo de carne de vacuno, aumento del de carnes blancas, especialmente de pollo, y recuperación de la demanda de pescado; vi) disminución de la demanda de leche líquida (excepto la de bajo contenido graso), aumento de la demanda de derivados lácteos (yogures, quesos, postres) y sustitución del consumo de mantequilla por margarina; vii) aumento de las comidas fuera de casa, especialmente en establecimientos de comida rápida; ${ }^{5}$ tendencia al aumento de restaurantes de tipo naturista, e incorporación de mesones de ensaladas en los restaurantes.

En general, estas tendencias tienden a generalizarse a medida que los países elevan su ingreso per cápita (gráfico 1).

GRAFICO 1

Mundo: El desarrollo y las tendencias del consumo de alimentos

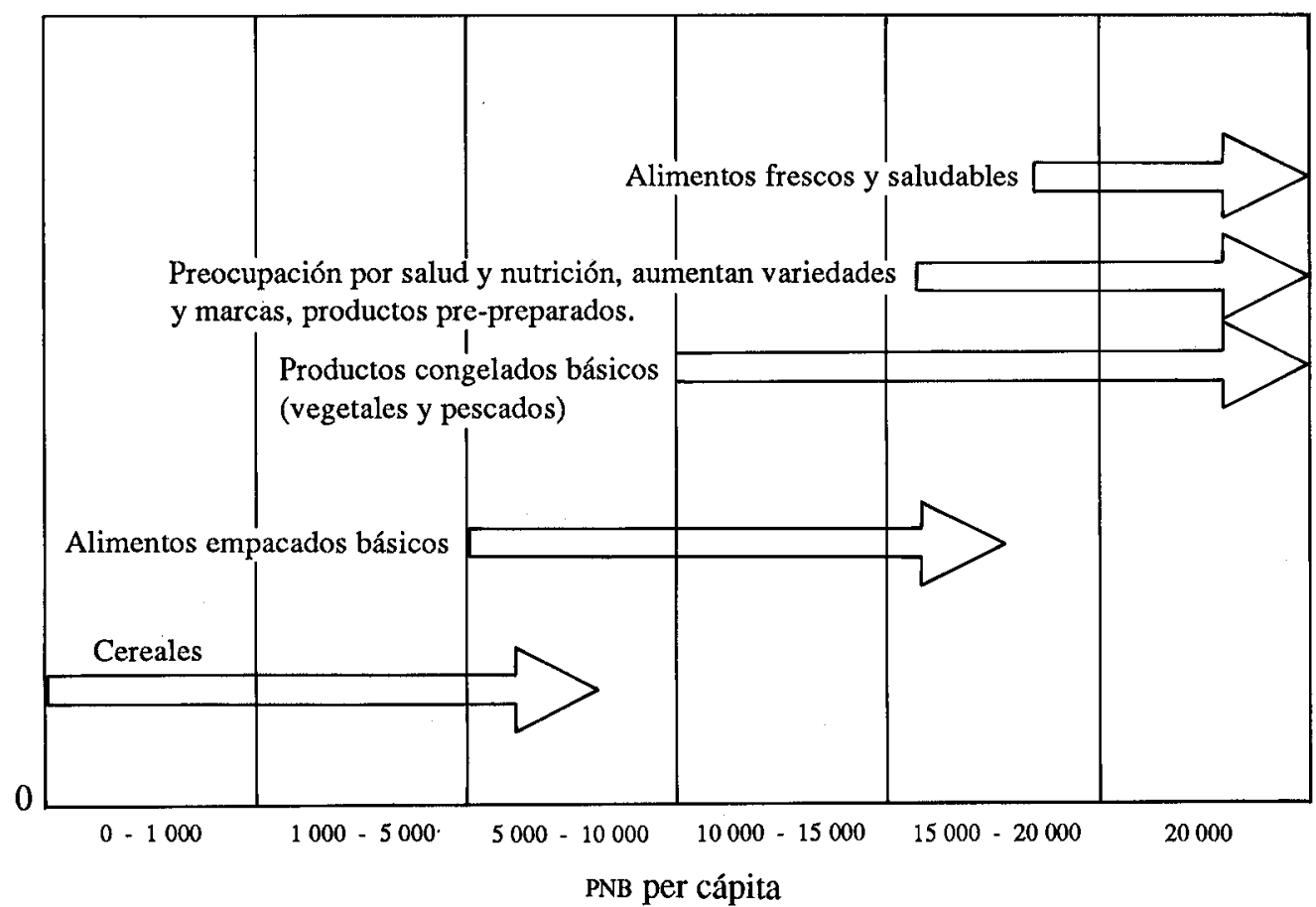

Fuente: The Economist, Londres, 4 de diciembre de 1993.

4 Estas tendencias han sido destacadas por la Comisión de las Comunidades Europeas (1991), Jones Putnam (1991), Reig (1992) y Lutz, Blaylock y Smallwood (1993).
5 En 1954, sólo el $4 \%$ del gasto en alimentos fuera de casa del estadounidense medio se realizaba en establecimientos de comida rápida. En la actualidad, dicho porcentaje es del $34 \%$ (Food Review, vol 14, $\mathrm{N}^{\circ} 3$, julio-septiembre de 1991). 
A niveles de ingreso per cápita bajos (inferiores a los 5000 dólares anuales), el consumo alimenticio abarca típicamente alimentos básicos - como los cereales-, en estado de procesamiento mínimo y que no se hallan sujetos a una estrategia comercial de diferenciación por marcas y calidades. Cuando el ingreso per cápita del país excede los 5000 dólares, la presencia de alimentos empacados - aunque de manera elemental-- se hace notoria. A niveles de ingreso per cápita más altos, la demanda de alimentos comienza a converger hacia los patrones de consumo que se resumieron más atrás. Es importante destacar, sin embargo, que estos patrones de consumo característicos de las economías industrializadas tienden a imitarse en los segmentos de mayores ingresos de los países menos desarrollados.

\section{La evolución del mercado mundial de produc- tos agrícolas}

Al examinar la evolución de las importaciones mundiales de productos agropecuarios en relación con las importaciones totales de mercancías en los últimos treinta años (gráfico 2), salta a la vista la constante pérdida de importancia relativa de las importaciones agropecuarias dentro del comercio mundial de mercancías. Así, mientras que al iniciarse los años sesenta las importaciones agropecuarias mundiales representaban más del $25 \%$ de las compras mundiales de mercancías, en la actualidad esa participación es de casi $10 \%$. Cabe señalar que la pérdida de importancia relativa de la agricultura en el comercio mundial debería ser normal en un mundo que avanza hacia el desarrollo económico: si la proporción de los alimentos en la composición del gasto de las personas disminuye a medida que el ingreso aumenta, y si se importa un porcentaje del gasto en alimentos (que para simplificar se puede asumir constante), cabe esperar que a medida que los países se desarrollan, sus importaciones agropecuarias (que reflejan su gasto en alimentos) disminuyan su participación relativa en las importaciones totales (las que, a su vez, estarían reflejando el comportamiento del gasto agregado de los países) ${ }^{6}$

6 A pesar de lo anterior, la literatura especializada tiende a considerar que esta tendencia a la baja ha sido exagerada en las últimas décadas debido a la alta intervención de los gobiernos en el comercio agrícola internacional. Véase, por ejemplo, Banco Mundial, 1986 y CEPAL, 1993a.
GRAFICO 2

Mundo: Participación de las importaciones de productos agropecuarios en las importaciones totales de mercaderias

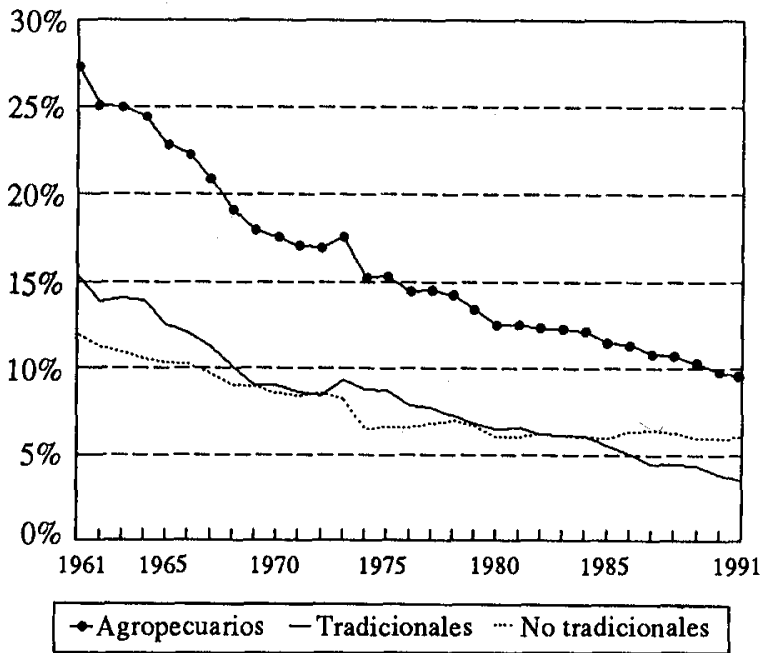

Fuente: Base de datos Agrostat, de la Organización de las Naciones Unidas para la Agricultura y la Alimentación (FAO). Elaboración de la Unidad de Desarrollo Agrícola de la CEPAL.

La segunda característica que interesa resaltar es el cambio en la estructura de las importaciones agropecuarias mundiales. Del gráfico 2 se deduce que los productos agropecuarios que en América Latina se consideran tradicionales han ido perdiendo importancia relativa en la composición de las importaciones agropecuarias mundiales en favor de las que se consideran no tradicionales. ${ }^{7}$ En efecto, mientras que en los años sesenta los productos tradicionales representaban, en promedio, el $54 \%$ de las compras agropecuarias mundiales, en la actualidad esa participación ha disminuido al $37 \%$. Los cambios en los patrones de consumo en los mercados mundiales y la intervención de los gobiernos en los mercados agrícolas han desempeñado un papel preponderante en esta evolución de las compras agrícolas mundiales, desincentivando la demanda de productos tradicionales y potenciando el desarrollo de los mercados no tradicionales.

7 Los productos agrícolas tradicionales son aquellos que entre las dos grandes crisis económicas del siglo XX integraron -en distintos subperíodos - la lista de los productos que representaron más de las tres cuartas partes de las exportaciones latinoamericanas. Los no tradicionales se definen por complemento. Véase un análisis más a fondo de estos conceptos en CEPAL, 1993a, cap. II. 


\section{II}

\section{La respuesta de América Latina a los cambios en los mercados agrícolas internacionales}

El comportamiento competitivo de un producto en determinado mercado suele medirse a través de la evolución de la proporción que en él representa. Según cálculos realizados a partir de la base de datos Agrostat de la FAO, la participación de los productos agropecuarios latinoamericanos ${ }^{8}$ en el comercio mundial bajó de $9.6 \%$ en la década de 1960 a poco más de $7 \%$ en la actualidad.

$\mathrm{Si}$ se distingue entre productos tradicionales y no tradicionales, se puede observar que la participación de América Latina en el mercado de los primeros, luego de bajar entre los años sesenta y los setenta de $14.2 \%$ a $12.8 \%$, ha tendido a mantenerse durante los últimos años en alrededor del $12.1 \%$. Sin embargo, dentro de los productos agropecuarios no tradicionales, América Latina ha venido ganando importancia mundial en la exportación de frutas y le- gumbres (que excluye las bananas, consideradas tradicionales). Así, las frutas y legumbres de América Latina, entre el decenio de 1960 y la actualidad, casi duplicaron su participación en el mercado mundial de estos productos.

Otra manera de medir el comportamiento competitivo de la oferta agrícola de exportación latinoamericana es la de analizar si -luego del inicio de los procesos de ajuste y apertura - ha habido cambios en su composición que respondan a las tendencias presentes en los mercados mundiales. Una forma simple de realizar dicha evaluación es la de graficar las tasas de crecimiento de distintas categorías de productos agrícolas durante el período posterior al desencadenamiento de la crisis y contrastarlas con las tendencias de consumo de los mercados.

El gráfico 3 (elaborado a partir del anexo 1)

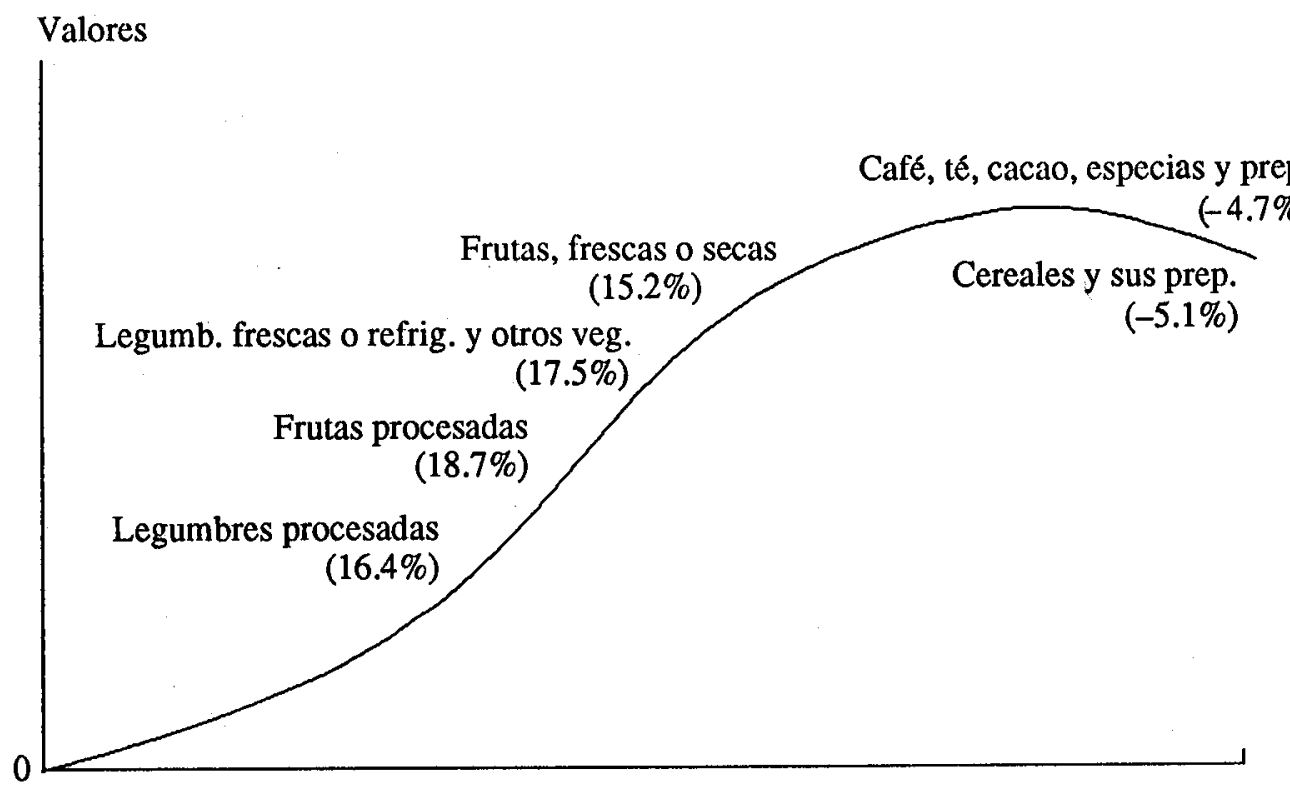

Tiempo

8 América Latina está representada por los 11 países miembros de la ALADI. 
presenta las tasas de crecimiento de algunas categorías importantes de productos agrícolas de exportación de la región ${ }^{9}$ durante el período 1983-1992. Lo que se observa allí es que un grupo de productos, los más dinámicos, se encontrarían en una fase de expansión en los mercados internacionales. Los menos dinámicos, en cambio, registrarían tasas de crecimiento negativas en el período, aunque sus valores de exportación son bastante significativos para la región. Ello, debido a que estos últimos productos pertenecerían a mercados internacionales consolidados y la etapa en la que se encontrarían dentro de su ciclo de vida sería, más bien, de estancamiento y declive.

Según el gráfico 3, las exportaciones agrícolas de América Latina habrían respondido positivamente a las tendencias de consumo que se han venido registrando en los mercados mundiales. Así, las mayores tasas de crecimiento anual medio de los valores exportados durante el período 1983-1992 se observaron en las frutas procesadas, en las legumbres frescas o refrigeradas y otros vegetales, en las legumbres procesadas y, finalmente, en las frutas frescas o secas. Por el contrario, los que mostraron el desempeño más negativo fueron los cereales y sus preparados y otros productos tradicionales, como el café y el algodón.

Del mismo modo, entre los productos pecuarios, la tasa anual media de crecimiento de las exportaciones de aves de corral y sus derivados $(8.3 \%)$ fue superior a la que registró la exportación de carne de bovino $(0.6 \%)$. Las exportaciones pesqueras también crecieron a un ritmo bastante superior que el promedio de las exportaciones agrícolas. El mayor dinamismo de los productos que aquí se han resaltado - que en su mayor parte responden a la categoría de no tradicionales-indica que la oferta exportadora de América Latina se ha ido adaptando a los cambiantes patrones de consumo en los mercados internacionales.

Sin embargo, a pesar de que los indicadores anteriores sugieren que el comportamiento de la oferta agrícola de exportación de América Latina durante el período posterior a la crisis ha tendido a adaptarse a los cambios que experimentan las condiciones de los mercados internacionales y que se ha posicionado bien dentro de los sectores más dinámicos, todavía el grueso de las exportaciones agrícolas regionales se debe a productos que responden a la estructura productiva

9 Diez países: Argentina, Bolivia, Brasil, Colombia, Chile, Ecuador, México, Paraguay, Uruguay y Venezuela. predominante en la región en el período anterior a los programas de ajuste y apertura.

En el gráfico 4 se muestra la evolución de la estructura de las exportaciones agrícolas latinoamericanas entre 1983 y 1992. De él se desprende que si bien los productos no tradicionales aumentaron sostenidamente su participación en la oferta agrícola exportable de la región (desde un quinto del total en 1983, hasta más de un tercio en la actualidad), la mayor parte de las exportaciones está constituida aún por productos tradicionales, cuyos mercados son los que menor dinamismo y mayores distorsiones presentan. (Véase el anexo 2.)

GRAFICO 4

América Latinaa: Exportaciones agrícolas, 1983-1992

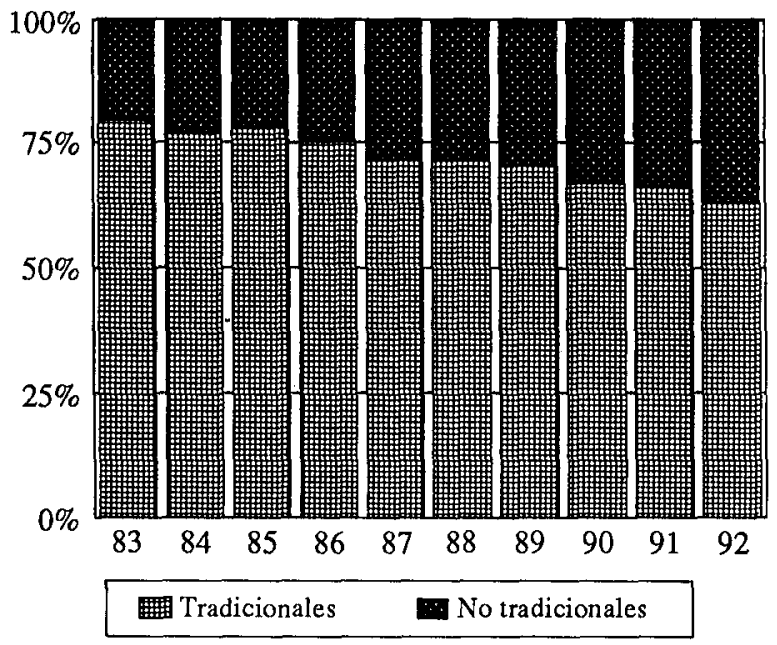

Fuente: Unidad de Desarrollo Agrícola, sobre la base del Banco de Datos del Comercio Exterior de América Latina y el Caribe (BADECEL), de la CEPAL.

a Diez países: Argentina, Bolivia, Brasil, Colombia, Chile, Ecuador, México, Paraguay, Uruguay y Venezuela.

Además, si se realiza un examen detallado de la composición de las exportaciones no tradicionales se aprecia que éstas - a pesar de que crecieron y se diversificaron en el período- abarcan todavía un número limitado de productos, concentrados en determinados países. Así, por ejemplo, dentro de la muestra de 10 países considerados en el gráfico 4 , en 1992 el $75 \%$ de las exportaciones de jugos de fruta y de legumbres perteneció a Brasil (básicamente jugo de naranja), el 95\% de las exportaciones de tomates de la región tuvo por origen México, el $86 \%$ de los embarques regionales de uvas salió desde Chile y el $82 \%$ de las exportaciones de flores y follaje cortado 
se generó en Colombia. También se observa que no existe una diversificación suficiente de los mercados receptores, lo que podría implicar cierta vulnerabilidad en el tiempo. ${ }^{10}$

\section{III \\ La intervención pública en la formulación de una estrategia de exportación agrícola competitiva}

En esta sección se analiza -en el contexto de la teoría económica - la intervención pública en el diseño de una estrategia competitiva orientada tanto a mejorar el desempeño de las exportaciones agrícolas regionales en los mercados internacionales, como a promover una diversificación de la oferta agrícola regional. Ello con la intención de facilitar la incorporación de los sectores agrícolas menos capitalizados (básicamente pequeños y medianos productores) a los beneficios de la agroexportación, especialmente de productos no tradicionales.

En lo que sigue se entiende por estrategia competitiva el diseño de un conjunto de medidas que busquen mantener en el largo plazo los beneficios económicos que derivan de la actividad exportadora en mercados internacionales. Estos beneficios deben estar en concordancia con los niveles de riesgo que —en una situación óptima- estaría dispuesta a asumir la empresa, país o región que exporta.

Sin embargo, antes de empezar a discutir la intervención pública en una estrategia de este tipo, conviene realizar una estilización de la dinámica de los productos agrícolas en los mercados internacionales.

\section{Lineamientos para una estrategia competitiva dinámica}

El gráfico 5 muestra los ciclos de vida de cuatro productos agrícolas que aparecen en el mercado in-

10 Véase un análisis detallado de las características de la oferta agrícola no tradicional de la región en CEPAL, 1993a, cap. III.

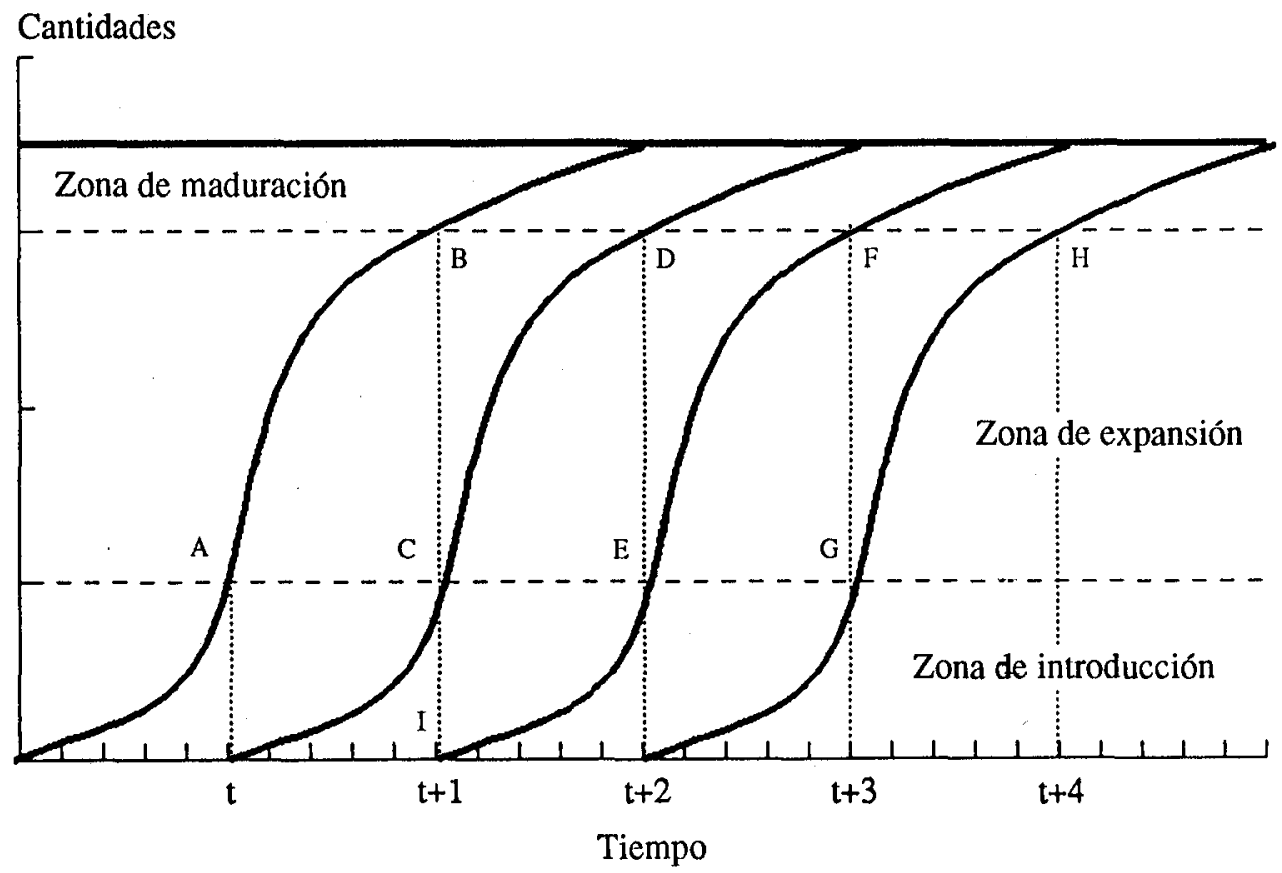


ternacional en cuatro momentos distintos. En general, cada ciclo de vida puede caracterizarse - de manera simplificada - por tres etapas: en la primera, se va desde la experimentación hasta la introducción de un producto nuevo en un mercado determinado; en la segunda, la demanda por el producto introducido en el mercado empieza a crecer hasta llegar a una etapa de maduración; por último, en la tercera la demanda del producto ya ha madurado y, por lo tanto, se estabiliza y hasta puede descender en el tiempo.

Estas tres etapas en los ciclos de vida de los productos agrícolas definen en el gráfico 5 tres zonas que han sido denominadas: de introducción, de expansión y de maduración. Cada una de ellas tiene niveles de rentabilidad y riesgo diferentes. La zona de introducción incorpora generalmente un alto nivel de riesgo asociado a la inversión inicial, pero también, si el producto tiene buena acogida en el mercado, puede significar una alta tasa de retorno por unidad de producto. ${ }^{11}$

La zona de maduración, en cambio, al estar caracterizada por mercados consolidados y estables (y en determinadas circunstancias, en declive), no implica generalmente mayor nivel de riesgo. La rentabilidad de la actividad exportadora en dicho caso está definida por los volúmenes exportados, dado que la tasa de retorno por unidad de producto es baja. Esta zona es característica de los productos de exportación "tradicionales".

Finalmente, la zona de expansión se halla en una situación intermedia, en la cual con un nivel de riesgo aceptable se obtiene buena rentabilidad por unidad de producto. Esta zona corresponde a mercados de productos aceptados por los consumidores pero cuya demanda, por alguna razón, excede a la oferta tradicional existente; por lo tanto, los costos de acceder a

\footnotetext{
11 Según datos del Departamento de Agricultura de los Estados Unidos, tan sólo en 1991 se introdujeron al mercado de ese país 12398 productos alimenticios nuevos. La mayoría de ellos son extensiones de otros que ya están en los mercados, mediante nuevos tamaños, sabores, diseños de empaque, etc. Muchos de estos productos alimenticios nuevos responden a las preocupaciones ecológicas y de salud de los consumidores. Introducir un nuevo producto en el mercado puede implicar gastos por más de 100 millones de dólares, los que se distribuyen en investigación y desarrollo, comercialización experimental, publicidad, manejo de inventarios y costos financieros. Aunque no existen datos precisos, según estimaciones de algunos analistas, de los productos nuevos que se introducen en el mercado estadounidense fracasa entre el $80 \%$ y el $95 \%$. Los que pasan la prueba, sin embargo, obtienen altas tasas de rentabilidad. Para mayores detalles, véase Gallo, 1992.
}

dicho mercado son menores que los de introducir un producto nuevo o exótico. ${ }^{12}$

Las tres zonas, por lo tanto, representan distintas combinaciones de riesgo y rentabilidad. Se supone, entonces, que en determinado momento (por ejemplo, en un punto cualquiera entre $t+1$ y $t+2$ en el gráfico 5), la estructura de las exportaciones agrícolas de un país está compuesta por tres tipos de productos. Uno que se encuentra en la zona de introducción, otro que se halla en la zona de expansión y otro que se ubica en la zona de maduración.

La ponderación de cada uno de los tipos de productos dentro de la estructura de las exportaciones agrícolas dependerá del grado de aversión al riesgo agregado que tiene el sector agrícola exportador del país. Sin embargo, si se considera que dicho nivel debiera ser "normal", sería de esperar que la mayor parte de las exportaciones se ubicara dentro de la zona de expansión y una menor parte se distribuyera entre las zonas de introducción y de maduración. En ese sentido, desde una perspectiva intertemporal, lo óptimo desde el punto de vista del país sería mantener su estructura de riesgo estable a lo largo del tiempo, con el correspondiente nivel de rentabilidad.

Tal estrategia implicaría, por ejemplo, que si determinados agentes exportadores quisieran mantenerse a lo largo del tiempo con un nivel de riesgo y rentabilidad media característico de la zona de expansión, deberían poder trasladarse de un producto a otro. Es decir, supóngase que en el período t cierto sector exportador (que puede ser caracterizado como una empresa individual) ingresa al mercado agrícola mundial y ofrece, por ejemplo, mangos. Como en ese momento dicha demanda está creciendo, a la empresa exportadora le convendrá mantenerse en el mercado por un tiempo (definido por el período entre $t \mathrm{y} t+1$ ) mientras prevalezcan las condiciones de riesgo y rentabilidad que optimizan su propia función de utilidad. Es decir, la estrategia óptima para dicha empresa entre el período t y $\mathrm{t}+1$ está determinada por el segmento $\mathrm{AB}$.

A partir del período $t+1$, sin embargo, las condiciones de riesgo y rentabilidad que caracterizaban al mercado del mango cambian, dado que este producto ingresa a la zona de maduración (con la concurrencia de muchas nuevas empresas este mercado). Cuando

12 Una de las características de esta etapa es que en ella, por ejemplo, ya existen circuitos de comercialización para el producto. 
la empresa se halla en un punto como el B se le abren las siguientes alternativas: a) Seguir produciendo mangos, pero dentro de la zona de maduración (con bajo riesgo y baja rentabilidad); b) cambiar de actividad productiva. Y aquí nuevamente tiene dos opciones: i) invertir en un producto nuevo (desconocido en el mercado), ubicándose en la zona de introducción -de alto riesgo y alta rentabilidad-, es decir, pasar del punto $\mathrm{B}$ al punto I; ii) invertir en un producto no tan nuevo (ya aceptado en el mercado) y mantenerse en la zona de expansión; es decir, pasar del punto B al punto $\mathrm{C}$.

Para la empresa exportadora que se ubica en un punto como B y decide cambiar de actividad productiva, este cambio no significa necesariamente que se desligue totalmente del producto anterior. El paso de B a C o I puede significar, efectivamente, un cambio de producto (por ejemplo, pasar de mangos a piñas), pero también puede implicar su diferenciación o transformación (por ejemplo, pasar de mangos a jugo de mango). El desafío principal para quienes formulan la política económica en la actualidad es el de cómo elaborar -dentro del modelo económico vigente - una estrategia de desarrollo de las exportaciones agrícolas que facilite a la empresa que se ubica en el punto $B$ seguir una trayectoria - que puede ser B, C, D, E, F, G, H- de forma tal que la acción del sector público favorezca la toma de decisiones del sector privado derivadas de una conducta optimizadora, en función de sus preferencias de riesgo y rentabilidad.

\section{La intervención pública en el diseño de una estrategia competitiva de exportaciones agrí- colas}

El diagnóstico de la crisis que afectó a América Latina en los años ochenta señalaba como una de sus causas determinantes el excesivo papel del Estado en la economía, en detrimento de la actividad privada (Balassa, Bueno, Kuczynski y Simonsen, 1986). Las medidas que acompañaron a los programas de ajuste y apertura en la región, por lo tanto, fueron concebidas con la intención de favorecer la competitividad de las empresas a través del establecimiento de un marco macroeconómico estable, la readecuación del tamaño y las funciones del Estado y un ordenamiento jurídico.

La participación específica del Estado en la promoción de la agricultura de exportación se limita, en ese contexto, a la provisión de infraestructura básica (caminos, puertos, cierto tipo de obras de riego); al registro, ordenación y difusión de estadísticas nacionales de producción y comercio exterior; a la generación y difusión de información sobre las condiciones climáticas presentes y futuras, y a la labor de velar por el mantenimiento de ciertas exigencias fitosanitarias y zoosanitarias, principalmente.

El propósito de las líneas que siguen, sin embargo, es analizar si la participación pública en el desarrollo de la agricultura de exportación en América Latina (haciendo hincapié en los productos no tradicionales) debería limitarse exclusivamente a los puntos antes mencionados, o si debería ampliarse. Esto es útil, sobre todo, si se tiene en cuenta que los sectores rurales de países como Ecuador, México, Perú o Venezuela reclaman una mayor participación en los beneficios de la estrategia de desarrollo emprendida.

Un estudio reciente publicado por el Banco Mundial (Jaffe, 1993), que analiza 15 experiencias exitosas con productos agrícolas de alto valor en nueve países en desarrollo, ${ }^{13}$ muestra que si bien en la mayoría de los casos el despegue exportador se dio paralelamente a la introducción de reformas macroeconómicas y comerciales, o después de ellas, en casi todos los casos los gobiernos desempeñaron un papel preponderante, al adoptar medidas de apoyo que facilitaron el éxito de las experiencias. La participación del sector público fue más allá de la provisión de infraestructura básica y abarcó programas de investigación y transferencia tecnológica, inspección y certificación del producto y, en más de la mitad de los casos, mejoramiento de la información pública. Otros elementos de la intervención pública que destaca dicho estudio son la negociación a nivel de gobiernos para acceder a ciertos mercados y la asistencia para promover el producto en los mercados internacionales. $^{14}$

\footnotetext{
13 Los casos que se citan son el de los tomates frescos de México; las hortalizas fuera de temporada de Kenya; los cítricos frescos de Israel; la fruta de zonas templadas, los tomates procesados y los productos pesqueros de Chile; el jugo concentrado congelado de naranja y los productos de la soya, de Brasil; la carne y los productos de la soya de Argentina; los productos avícolas, la tuna y los camarones de Tailandia, y, finalmente, los alimentos procesados de alto valor taiwaneses.

14 La exitosa experiencia de la fruticultura de exportación chilena en los últimos 15 años (ejemplo frecuentemente citado sobre los beneficios potenciales de la agricultura de exportación) fue resultado de un esfuerzo conjunto entre el sector público y el sector privado a lo largo de varias décadas. El papel del Estado en la inversión en tecnología y capital humano, en la identificación de variedades idóneas, en la disponibilidad de crédito, etc., fue funda-
} 
El análisis que sigue respecto a la participación del sector público en el diseño de una estrategia competitiva para la exportación agrícola se hace en el contexto de la teoría económica, en especial de los avances recientes de la teoría del desarrollo económico. A diferencia del enfoque más tradicional del modelo Arrow-Debreu, en el que el equilibrio competitivo no acepta la presencia de otras instituciones que no sean el mercado y los derechos de propiedad, la visión del desarrollo agrícola que se impone actualmente en los centros académicos más importantes a nivel internacional -denominada "teoría de las instituciones agrarias" (De Janvry, 1994) o "economía de las organizaciones rurales" (Hoff, Braverman y Stiglitz, 1993) - señala que la existencia de otras instituciones económicas en el sector agrícola o rural refleja respuestas racionales de los agentes económicos a problemas en los mercados.

Si bien ambos enfoques postulan la racionalidad económica -entendida como un proceso en el que, dadas diferentes restricciones de recursos, los agentes económicos adoptan las mejores decisiones posibles respecto a su propio bienestar- la diferencia entre ellos radica en la optimalidad social del equilibrio obtenido. Según el modelo Arrow-Debreu, la suma de decisiones privadas llevan a un equilibrio que es socialmente eficiente. ${ }^{15} \mathrm{La}$ teoría de las organizaciones rurales, en cambio, sostiene que el equilibrio que deriva de procesos optimizadores individuales no es necesariamente eficiente desde una perspectiva social, puesto que los mercados no son perfectos. Las fallas de mercado en las cuales se centra este último enfoque provienen, básicamente, de la ausencia de ciertos mercados (por ejemplo, el de riesgo), de la existencia de información imperfecta y de los costos de transacción en la economía. Así, la intervención pública en un contexto de mercados que no son perfectos puede generar mejoras de eficiencia para la sociedad en su conjunto si ella se focaliza en acciones que son rentables desde una perspectiva social, pero que no lo son desde un punto de vista privado (Hoff, Braverman y Stiglitz, 1993).

En el presente artículo se sostiene que en el contexto latinoamericano actual —en el que la mayoría

mental para que luego del ajuste y la posterior apertura al exterior se registraran resultados espectaculares. Esta experiencia se detalla, entre otros, en los trabajos de CEPAL, 1990; Jarvis, 1992 y Legarraga, 1993.

15 La eficiencia se entiende en el sentido que le da Pareto, según el cual ninguno de los individuos de la sociedad puede estar mejor sin que al menos uno esté peor. de las economías se encuentran relativamente abiertas al exterior y desreguladas-- subsisten imperfecciones en los mercados, fundamentalmente de orden microeconómico, que dificultan la incorporación de los sectores agrícolas menos capitalizados a la estrategia de desarrollo basada en las exportaciones. De conformidad con el modelo descrito en el apartado 1 de esta sección, tales imperfecciones dificultarían, por ejemplo, el paso del punto $\mathrm{B}$ al punto $\mathrm{C}$ a aquella empresa que - como consecuencia de un proceso optimizador- decidió seguir una estrategia dinámica definida por la trayectoria A, B, C, D, E, F, G, H.

Para trasladarse del punto $\mathrm{B}$ al $\mathrm{C}$ el productor agrícola necesita disponer de información suficiente sobre los mercados que le permita minimizar los riesgos asociados a su decisión de cambiar de rubro (por ejemplo, condiciones de oferta y demanda en los mercados internos y externos, tendencias del consumo, barreras proteccionistas, evolución de los precios, etc.). Una vez que, con esa información y de acuerdo a sus preferencias, identifica el producto característico del punto $\mathrm{C}$, el productor necesita tener la capacidad técnica y financiera para elaborarlo. Además, debiera sentir la tranquilidad de que su posición competitiva en los mercados internacionales es respaldada por la calidad del producto que entrega. Y finalmente, sobre todo si su escala de producción es pequeña o mediana, debiera poseer cierta capacidad negociadora - tanto interna como externa - que le permita, de un lado, compartir riesgos en el proceso de comercialización de productos y, de otro, lograr la apertura de mercados que se mantenían cerrados.

\section{a) El desarrollo de los mercados de información}

La apertura al exterior de las economías latinoamericanas ha hecho que las necesidades de información de las empresas exportadoras para competir eficientemente en los mercados internacionales vayan más allá de la información que generalmente proporciona el sector público como parte de sus actividades corrientes (estadísticas nacionales, condiciones climáticas, etc.). Se sabe por experiencia que si los agentes económicos no cuentan con la información necesaria, sus decisiones de producción y exportación pueden ser subóptimas y afectar el bienestar de la sociedad en su conjunto. ${ }^{16}$ Por lo tanto, es esencial para las empresas y los países poder dispo-

\footnotetext{
16 Ello se ilustra claramente en el conocido "dilema de los prisio-
} neros" cuando se llega a un equilibrio competitivo o de Nash. 
ner oportunamente de información (estadística y coyuntural) respecto a la situación de los mercados internacionales, al menos en lo que toca a la evolución de los precios, el comportamiento de la demanda, las restricciones de acceso a los mercados y la situación de los potenciales competidores.

A esta información acceden generalmente las empresas grandes que cuentan con un sistema operativo para tal efecto, o que poseen los recursos suficientes para contratar los servicios de una o más empresas especializadas en este tipo de información. Para las empresas de menor tamaño, sin embargo, el alto costo de obtener la información básica para tomar la decisión de integrarse a los mercados de exportación puede hacerlas desistir de tal esfuerzo. De ahí que, dado el carácter de bien público de la información para las empresas de menor escala, convendría que el sector público proveyera la información básica, sobre todo si sus costos de generación -dado que cuenta con representaciones diplomáticas en el mundo- son marginales.

Un ejemplo que ilustra la necesidad de información sobre los mercados internacionales para maximizar los beneficios de la agricultura de exportación surge de un sondeo realizado por la Unidad de Desarrollo Agrícola de la CEPAL sobre la situación de los cultivos de exportación no tradicionales en 14 países de América Latina: Argentina, Bolivia, Colombia, Costa Rica, Ecuador, El Salvador, Guatemala, Honduras, México, Nicaragua, Paraguay, Perú, la República Dominicana y Uruguay. Varios de estos países están realizando esfuerzos de promoción (públicos o privados) en un rango bastante reducido de productos.

Así, por ejemplo, ocho países de la región planean expandir su participación en los mercados de los berries y de los cítricos. Siete países tienen altas expectativas de aumentar sus exportaciones de mangos, melones, y flores y follaje cortados. Al menos seis distintos grupos de países ven con especial interés la posibilidad de incrementar sus ofertas en los mercados mundiales de espárragos y piñas. Los resultados de estas estrategias de los distintos países, elaboradas a partir de la situación pasada en los mercados mundiales de dichos productos, pueden llegar a saturar algunos de ellos si se excede su capacidad de demanda. Esto mermaría los avances en materia de bienestar esperados de estos esfuerzos de promoción.

b) La investigación y la transferencia tecnológica

Una de las características de las políticas de ajuste estructural aplicadas en América Latina ha sido la reducción del gasto fiscal. Con tal disminución, las instituciones públicas y semipúblicas dedicadas a la investigación agrícola vieron recortados sus presupuestos y perdieron espacio y presencia (CEPAl, 1991, p. 45). Esta reducción del financiamiento público habría originado un nivel de inversión en investigación y desarrollo tecnológico inferior al que se consideraría socialmente deseable.

En un estudio reciente (Jarvis, 1992) se argumenta que, siendo el cambio tecnológico el principal factor de crecimiento agrícola sostenido y dado el carácter de bien público que tiene el conocimiento obtenido de la investigación agrícola, si los mercados tienden a ser competitivos los inversionistas privados sólo pueden apropiarse de una porción de los beneficios de la investigación. De ahí que en entornos macroeconómicos desregulados y que favorecen la competencia empresarial, los gastos en investigación y desarrollo agrícola emprendidos por el sector privado pueden situarse por debajo de lo que - desde una perspectiva social- puede considerarse óptimo. En ese sentido, Jarvis sugiere que la intervención pública en la investigación agrícola debiera ser necesaria, ya sea que se efectúe directamente o a través de subsidios para la investigación privada. Sin embargo, la participación pública no debiera limitarse solamente al desarrollo de tecnología, sino abarcar también el estudio de nuevos productos exportables y la identificación de nichos en los mercados internacionales. ${ }^{17} \mathrm{Si}$ las estrategias de desarrollo seguidas por los países de la región consideran la incorporación de sectores poco capitalizados a los beneficios que otorga la agricultura de exportación, no es conveniente que las empresas asuman individualmente los costos de investigación y desarrollo tecnológico. Sería más eficiente tratar de aprovechar las economías de escala que emanarían de la realización conjunta de ese esfuerzo.

c) La capacidad de financiamiento de proyectos por parte de los productores agrícolas

En el pasado, tanto América Latina como otras regiones encararon la falta de financiamiento mediante la creación de bancos especiales para la agricultura. En general, la propiedad y la gestión de estas instituciones especializadas en América Latina correspon-

\footnotetext{
17 Cabe destacar que, en la actualidad, campos tan diversos como la medicina, la cosmética y la agroindustria pueden constituirse en interesantes alternativas de destino para los productos agrícolas de exportación no tradicional.
} 
dieron al Estado. Sin embargo, dado que su funcionamiento se dio en un entorno macroeconómico altamente distorsionado y estuvo acompañado de medidas poco aconsejables para resolver los problemas del financiamiento agrícola, estas instituciones públicas generaron crecientes déficit y altas ineficiencias en la asignación del crédito.

Por esta razón, al iniciarse los programas de desregulación y apertura en la región, los bancos agrícolas —en muchos casos - fueron desarticulados. Hoy, cuando la banca comercial privada de la mayoría de los países de la región se encuentra desregulada, los productores agrícolas - sobre todo los pequeños y medianos - tienen acceso muy limitado al crédito comercial. $^{18}$

Este racionamiento del crédito ${ }^{19}$ no se debe a la existencia de controles o techos a las tasas de interés, a tasas de encaje excesivamente altas o a la obligatoriedad de mantener ciertas líneas de crédito subsidiadas —que son las razones clásicas esgrimidas en estudios como los de Mc Kinnon (1974) y Shaw (1973) - , sino a factores como la ausencia de capital de respaldo del crédito y problemas de asimetría en la información.

Los problemas de asimetría en la información surgen cuando la empresa que pide el crédito posee más información que el banco respecto a la probabilidad de éxito de su proyecto. ${ }^{20}$ Para los bancos es difícil y costoso obtener esa información porque, en general, la rentabilidad de los proyectos agrícolas depende de muchos aspectos: la calidad del suelo, las condiciones del clima, la tecnología aplicada, la variedad del producto, la localización de su demanda (mercado interno o externo), la variabilidad de los precios (que tiene que ver con la estacionalidad de la producción y la intervención en los mercados), la disponibilidad de agua, el acceso a infraestructura de almacenamiento y transporte (caminos, puertos), su

\footnotetext{
18 En Debate Agrario, 1993, se analizan los problemas del crédito agrario en Bolivia, Colombia, México, Perú y Venezuela, luego de los programas de ajuste y apertura.

19 Se entiende por racionamiento de crédito aquella situación en la que el mercado financiero no otorga crédito a todos los agentes que lo solicitan, aun cuando éstos estén dispuestos a pagar el costo de oportunidad de los recursos.

20 Si el banco tuviera la certeza de que la empresa solicitante del crédito no tiene la posibilidad de engaño cuando se le solicita información relacionada con el proyecto que desea ejecutar, entonces no existiría problema de asimetría en la información. Sin embargo, la posibilidad de mentir existe y los costos en los que debería incurrir el banco para verificar si el productor mintió o no son bastante altos.
}

interacción con la agroindustria, la estructura del sistema de comercialización, y otros.

La incapacidad del sistema financiero para monitorear cada proyecto individualmente, debido a lo complejo de la información requerida, hace que la banca comercial privada - aun en situación de mercados financieros libres - no satisfaga las necesidades de financiamiento de los productores agrícolas, puesto que la expansión del crédito a este sector -en un contexto de información incompleta - aumentaría el nivel de riesgo y llevaría a reducir la rentabilidad esperada de los bancos

Si ante un exceso de demanda de crédito y en presencia de asimetrías en la información, la banca comercial decide aumentar las tasas de interés para llegar a más proyectos, es posible que los proyectos más seguros (de menor riesgo) se retiren del mercado financiero, quedando en él los más riesgosos. Con esto se alteraría la composición de la cartera de los bancos, disminuyendo su rentabilidad esperada (Stiglitz y Weiss, 1981).

La falta de financiamiento obliga a los productores -especialmente a los pequeños y medianos- a buscar recursos en el sector informal, en las agroindustrias o en los proveedores de insumos, o bien a autofinanciarse, o - en el peor de los casos- a postergar sus proyectos.

Lo expuesto ha hecho que en la agricultura se registren niveles de inversión inferiores al que se consideraría optimo desde el punto de vista social. De ahí que sea necesario formular políticas públicas que tiendan a eliminar o contrarrestar los factores que originan el racionamiento de crédito en el sector.

\section{d) La calidad de los productos exportables}

Después del ajuste y la apertura, la posición competitiva de América Latina en los mercados agrícolas internacionales, tanto de bienes tradicionales como no tradicionales, se basa en general en productos de bajo costo y baja calidad. Las ventajas comparativas en la producción de los bienes agrícolas regionales de exportación que se destinan a los países industrializados radican fundamentalmente en el bajo costo de la mano de obra, la estacionalidad de las cosechas y la relativa exclusividad de la producción, sobre todo en productos de clima tropical.

Estas ventajas, sin embargo, no son suficientes para sostener una estrategia de desarrollo sectorial de mediano y largo plazo. La experiencia ha demostrado que a medida que las zonas deprimidas van saliendo de su estancamiento, el costo de oportunidad de la 
mano de obra tiende a aumentar, reflejándose en mayores salarios. Por lo tanto, si no se realiza un esfuerzo por avanzar desde una posición competitiva de bajo costo y baja calidad, hacia una de alto valor y alta calidad, la oferta agrícola exportadora de la región tenderá a perder importancia relativa en los mercados internacionales. Los otros dos factores en los que radican las ventajas comparativas actuales de América Latina - la estacionalidad de las cosechas y la relativa exclusividad en la generación de ciertos productos- podrían debilitarse a mediano y largo plazo, a medida que más países en desarrollo se embarquen en estrategias agrícolas exportadoras y continúen los avances de la biogenética y la biotecnología. Además, la tendencia de los consumidores en los países más desarrollados apunta a privilegiar productos de alta calidad en lugar de los de bajo costo. Por lo tanto, es necesario hacer todo lo posible por exportar calidad y no sólo bajos precios, para que esta estrategia exportadora pueda mantenerse más allá del corto plazo.

La participación pública en este contexto estaría encaminada a proteger a aquellos exportadores que inviertan en mejorar la calidad de sus productos a costos que sean competitivos en el mercado internacional, ya que, tal como lo resaltaba Akerlof a principios de los años setenta, uno de los principales problemas de la comercialización de los productos agrícolas en las economías en desarrollo es el hecho de que los productos de baja calidad comercializados por los agentes "deshonestos" tienden a desplazar del mercado a los de buena calidad (Akerlof, 1970). La respuesta de los agentes privados a este problema en las economías de mercado es la introducción de "marcas" que identifiquen el producto y garanticen su calidad. Ello, sin embargo, se observa, básicamente, en economías que han pasado cierto nivel de ingreso per cápita o en aquellas -como Sudáfrica o Nueva Zelanda- en las que el Estado asume el monopolio de la comercialización del producto. En América Latina, la participación pública orientada a resguardar la calidad de los productos agarícolas de exportación podría efectuarse, por ejemplo, otorgando un sello que asegure la calidad del producto de las empresas que satisfacen ciertos estándares establecidos por alguna institución especializada (pública o privada) reconocida en los mercados importadores. Este sello sería diferenciado y se otorgaría tomando en cuenta tanto las exigencias fitosanitarias y zoosanitarias de los mercados de destino de los embarques, como la calidad exigida por los consumidores según el segmento en que se encuentran, para no perjudicar a aquellos productores que opten por orientar su producción a segmentos de consumo que privilegian un menor precio por sobre la calidad.

\section{e) La capacidad de negociación}

Hoy la mayoría de los países de la región procuran integrarse de manera creciente a los mercados internacionales, por lo cual es preciso que la oferta exportadora local cuente con cierta capacidad de negociación en los mercados de destino.

Esta capacidad de negociación debe orientarse, en primer lugar, a la defensa del espacio ganado en los mercados internacionales ante medidas proteccionistas en contra de los productos de exportación que excedan los límites establecidos por el GATT (GATT, 1993). En segundo lugar, a la conquista de mercados específicos -como el japonés-, en los cuales las negociaciones bilaterales a nivel de gobiernos (por ejemplo, acerca del tratamiento fitosanitario y zoosanitario aplicable a los productos exportables) desempeñan un papel decisivo. $Y$ en tercer lugar, a la comercialización de los productos en los mercados internacionales. La falta de agrupación y coordinación entre los productores hace que muchas veces los riesgos inherentes al comercio de bienes perecibles sean asumidos casi en su totalidad por ellos mismos, sobre todo en la medida en que la organización de la producción es competitiva, mientras que la estructura de la comercialización es oligopólica. En este caso, la actividad pública debiera fomentar, por ejemplo, el desarrollo de asociaciones dedicadas al comercio de productos, o favorecer la competencia en los sectores relacionados con la comercialización de los productos (Hill y Bender, 1993).

\section{Bibliografía}

Akerlof, G. (1970): The market for lemons: Qualitative uncertainty and the market mechanism, Quarterly Journal of Economics, $\mathrm{N}^{\circ} 84$.
Balassa, B., G. Bueno, P.P. Kuczynski y M.E. Simonsen (1986): Hacia una renovación del crecimiento económico en América Latina, Washington, D.C., Institute for International Economics. 
Banco Mundial (1986): Informe sobre el desarrollo mundial 1986 , Washington, D.C.

(1992): Informe sobre el desarrollo mundial 1992, Washington, D.C.

Basu, K. (1984): The Less Developed Economy: A Critique of Contemporary Theory, Oxford, Reino Unido, Basil Blackwell.

Blanchard, O.J. y S. Fischer (1989): Lectures on Macroeconomics, Cambridge, Massachusetts, MIT Press

Braverman, A. y J.L. Guasch (1989): Rural Credit in Developing Countries, Policy, Planning and Research Working Papers, $\mathrm{N}^{\circ} 219$, Washington, D.C., Banco Mundial.

Bustillo, I. y N. Barret (1993): Productividad y trabajo de la mujer en los Estados Unidos, Revista de la CEPAL, $\mathrm{N}^{\circ} 51 \mathrm{LC} / \mathrm{G}$. 1792-P, Santiago de Chile, Naciones Unidas, diciembre.

Carter, M.R. (1988): Equilibrium credit rationing of small farm agriculture, Journal of Development Economics, vol. 28, Amsterdam, Elsevier Science Publishers B.V. (North-Holland).

CEPAL (1978): 25 años en la agricultura de América Latina: Rasgos principales 1950-1975, Cuadernos de la CEPAL, $\mathrm{N}^{\circ} 21$, Santiago de Chile.

(1990): La cadena de distribución y la competitividad de las exportaciones Latinoamericanas: La fruta de Chile, LC/G. 1939, Santiago de Chile.

(1991): Los nuevos escenarios agrícolas en formación LC/ R. 111, Santiago de Chile.

(1993a): La apertura y los procesos agroexportadores recientes LC/R. 1299, Santiago de Chile.

(1993b): América Latina: Comercio exterior según la Clasificación Industrial Internacional Uniforme de todas las Actividades Económicas (CIUU). Cuadernos Estadísticos de la CEPAL, $N^{\circ} 19$, Santiago de Chile, septiembre. Publicación de las Naciones Unidas, $\mathrm{N}^{\circ}$ de venta S.93 II.G.10.

Comisión de las Comunidades Europeas (1991): Estudio del mercado de la CEE para frutas, cítricos y hortalizas, EC Ref. $\mathrm{N}^{\circ} \mathrm{CC} / \mathrm{ALA} / 930 / \mathrm{A} 2 / 91 / 273$ (Request $\mathrm{N}^{\circ} 2230$ ), tomo II.

Debate agrario (1993): N ${ }^{\circ} 16$, Lima, Centro Peruano de Estudios Sociales (CEPES), enero-abril 1993.

De Janvry, A. (1994): Social and economic reforms: The challenge of equitable growth in Latin America Agriculture, E. Muchnik y A. Niño de Zepeda (eds.), Apertura económica, modernización y sostenibilidad de la agricultura, IV Congreso Latinoamericano y del Caribe de Economía Agrícola, enero.

Figueroa, A. (1991): Desarrollo agrícola en la América Latina, Osvaldo Sunkel (comp.), El desarrollo económico desde dentro: Un enfoque neo-estructuralista para la América Latina, Lecturas, $N^{\circ} 71$, México, D.F., Fondo de Cultura Económica, S.A. de C.V.

Food Review (varios números): Washington, D.C., Departamento de Agricultura (Estados Unidos).

(1991): vol. 14, issue 3, Washington, D.C., Departamento de Agricultura (Estados Unidos), julio-septiembre.

Friedman, J. y C. Revoredo (1993): Relevancia del desarrollo económico, Persona y Sociedad, vol. VII, N ${ }^{\circ} 2-3$, Santiago de Chile, Instituto Latinoamericano de Doctrina y Estudios Sociales (ILADES).

Gallo, A. (1992): Record number of new products in 1991, Food Review, vol. 15, issue 2, Washington D.C., Departamento de Agricultura (Estados Unidos), julio-septiembre.

GATT (Acuerdo General sobre Aranceles Aduaneros y Comercio) (1993): Acta final en que se incorporan los resultados de la Ronda Uruguay de negociaciones comerciales multilaterales. MTN/FA (UR-93-0246), distribución especial, 15 de diciembre.

Hill, L. y K. Bender (1993): Developing the Regulatory Environment for Competitive Commodity Markets, trabajo presentado al FAO/World Bank Seminar in Agricultural Price Stabilization. Santiago de Chile.

Hoff, K., A. Braverman, y J. Stiglitz (eds.) (1993): The Economics of Rural Organization: Theory, Practice and Policy, Washington D.C., Banco Mundial.

Jaffe, S. (1993): Exporting High-Value Food Commodities: Success Stories from Developing Countries, World Bank Discussion Papers, $N^{\circ} 198$, Washington D.C., Banco Mundial.

Jarillo, J. C. y J. Martínez (1991): Estrategia internacional: Más allá de la exportación, Madrid, Mc Graw-Hill.

Jarvis, L. (1992): Cambios en los roles de los sectores público y privado en el desarrollo tecnológico: Lecciones a partir del sector frutícola chileno, Colección Estudios CIEPLAN, $\mathrm{N}^{\circ} 36$, Santiago de Chile, Corporación de Investigaciones Económicas para Latinoamérica (CIEPLAN), diciembre.

Jones Putnam, J. (1991): Food consumption, 1970-1990, Food Review, vol. 14, issue 3. Washington, D.C., Departamento de Agricultura (Estados Unidos), julio-septiembre.

Legarraga, M. (1993): Desarrollo frutícola en Chile, LC/R. 1312 (Sem.74/2), Seminario sobre la transformación de la producción agrícola en Paraguay (Asunción, 2 al 4 de noviembre), Santiago de Chile, CEPAL.

Lutz, S., J. Blaylock, y D. Smallwood (1993): Household characteristics affect food choices, Food Review, vol. 16, issue 2, Washington, D.C., Departamento de Agricultura (Estados Unidos), mayo-agosto.

Manchester, A. (1991): Food Spending, Food Review, vol. 14, issue 3, Washington D.C., Departamento de Agricultura (Estados Unidos), julio-septiembre.

Mc Kinnon, R.I. (1973): Dinero y capital en el desarrollo económico, México, D.F., Centro de Estudios Monetarios Latinoamericanos.

Méndez, J. (1991): The Development of the Colombian Cut Flower Industry, Policy, Research and External Affairs Working Papers, $\mathrm{N}^{\circ}$ 660, Washington, D.C., Banco Mundial, mayo.

Muchnik, E. y A. Niño de Zepeda, (eds.) (1994): Apertura económica, modernización y sostenibilidad de la agricultura, IV Congreso Latinoamericano y del Caribe de Economía Agrícola, Santiago de Chile, Ministerio de Agricultura, enero.

PNUD (Programa de las Naciones Unidas para el Desarrollo) (1993): Informe sobre el desarrollo humano, 1993, Madrid, Centro de Comunicación, Investigación y Documentación entre Europa, España y América Latina (CIDEAL).

Primo Braga, C. A. y S. Davi Silber (1991): Brazilian Frozen Concentrated Orange Juice: The Folly of Unfair Trade Cases. Policy, Research and External Affairs Working Papers, $\mathrm{N}^{\circ}$ 687, Washington, D.C., Banco Mundial, mayo.

Reig, E. (1992): Estructura del consumo alimentario y desarrollo económico, Investigación agraria: Economía, vol. 7, № 2, Madrid, Ministerio de Agricultura, Pesca y Alimentación, Instituto Nacional de Investigación y Tecnología Agraria y Alimentaria, diciembre.

Schwartz, K. (1988): Household trends in Europe after World War II, Keilman, Kuijsten y Vossen (eds.), Modelling Household Formation and Dissolution, Oxford, Reino Unido, Clarendon Press.

Shaw, E.S. (1973): Financial Deepening in Economic Development, Nueva York, Oxford University Press.

Stiglitz, J.E. y A. Weiss (1981): Credit rationing in markets with imperfect information, American Economic Review, vol. 71, $\mathrm{N}^{\circ}$ 3, Los Angeles, California, American Economic Association.

The Economist (1993): Londres, 4 de diciembre.

Vargas, G. (1993): Oportunidades y potencialidades de la fruticultura de exportación, Panorama económico de la agricultura, Santiago de Chile, Pontificia Universidad Católica de Chile.

Varian, H. (1992): Análisis microeconómico, Barcelona, España, Antoni Bosch, $3^{\mathrm{a}}$ edición.

Von Hesse, M. (1993a): Las exportaciones agrícolas no tradicionales: Un análisis de su relevancia en el actual proceso de desarrollo de Latinoamérica, ILADES/Georgetown University.

(1993b): El desarrollo agrícola en una economía de mercado, Temas del desarrollo rural. Santiago de Chile, La voz del campo. 


\section{América Latina (10 paises): ${ }^{a}$ Exportaciones agrícolas, 1983-1992}

\begin{tabular}{|c|c|c|c|c|c|c|c|c|c|c|}
\hline & \multicolumn{10}{|c|}{ A. Exportaciones agrícolas totales, en millones de dólares } \\
\hline & 1983 & 1984 & 1985 & 1986 & 1987 & 1988 & 1989 & 1990 & 1991 & 1992 \\
\hline Exportaciones de cultivos & 13749 & 16205 & 15552 & 15356 & 13335 & 15218 & 15256 & 17274 & 17200 & 18283 \\
\hline Frutas frescas o secas & 766 & 834 & 1073 & 1195 & 1333 & 1505 & 1641 & 2013 & 2712 & 2745 \\
\hline Nueces comestibles, frescas o secas & 114 & 107 & 160 & 167 & 143 & 169 & 165 & 205 & 194 & 259 \\
\hline Legumbres frescas o refrigeradas & 419 & 575 & 525 & 846 & 602 & 683 & 628 & 1207 & 1097 & 1791 \\
\hline Cereales y preparados de cereales. & 3156 & 2492 & 2468 & 1408 & 897 & 1156 & 1384 & 1786 & 1490 & 1964 \\
\hline Café, té, cacao, especias y sus preparados & 5302 & 6507 & 6568 & 7721 & 5688 & 5571 & 4881 & 4051 & 4097 & 3445 \\
\hline Azúcar, preparados de azúcar y miel & 957 & 893 & 596 & 700 & 664 & 847 & 773 & 1064 & 911 & 1067 \\
\hline Algodón & 433 & 508 & 457 & 229 & 400 & 564 & 724 & 781 & 839 & 412 \\
\hline Semillas y frutos oleaginosos. & 790 & 1567 & 1650 & 992 & 1066 & 1561 & 1820 & 2082 & 1773 & 1818 \\
\hline Productos vegetales en bruto & 208 & 224 & 231 & 252 & 266 & 344 & 400 & 441 & 530 & 636 \\
\hline Legumbres & 847 & 1718 & 1016 & 1014 & 1311 & 1692 & 1680 & 2284 & 1755 & 2055 \\
\hline Legumbres & 85 & 105 & 100 & 117 & 149 & 177 & 285 & 309 & 306 & 334 \\
\hline Frutas procesadas & 54 & 69 & 55 & 76 & 104 & 114 & 138 & 185 & 204 & 253 \\
\hline Otras frutas y legumbres procesadas & 708 & 1545 & 860 & 821 & 1058 & 1401 & 1258 & 1791 & 1245 & 1468 \\
\hline Bebidas y tabaco. & 700 & 727 & 763 & 757 & 876 & 1013 & 1077 & 1267 & 1676 & 1918 \\
\hline Productos y preparados comestibles diversos & 57 & 52 & 48 & 76 & 89 & 113 & 84 & 93 & 125 & 172 \\
\hline Exportc & 2380 & 1924 & 1892 & 2081 & 2164 & 2575 & 2627 & 3029 & 3041 & 3121 \\
\hline Animales vivos, principalmente para alimentación & 217 & 127 & 192 & 294 & 217 & 232 & 277 & 440 & 442 & 407 \\
\hline Carnes y preparados de carne & 1747 & 1446 & 1370 & 1408 & 1543 & 1794 & 1786 & 2003 & 2188 & 2323 \\
\hline Productos lácteos y huevos de ave. & 88 & 40 & 49 & 70 & 59 & 105 & 200 & 199 & 151 & 122 \\
\hline Lana y otros pelos de animales (excepto tops) & 293 & 282 & 246 & 261 & 302 & 380 & 294 & 317 & 194 & 181 \\
\hline Productos animales en bruto & 35 & 30 & 37 & 47 & 44 & 64 & 70 & 69 & 66 & 88 \\
\hline \multicolumn{11}{|l|}{ Exportaciones aceites, grasas, harinas y ceras, } \\
\hline Aceites y grasas de origen animal & 31 & 45 & 48 & 33 & 28 & 41 & 36 & 29 & 41 & 28 \\
\hline Aceites y grasas fijos de origen vegetal & 1121 & 1779 & 1809 & 897 & 964 & 1340 & 1375 & 1613 & 1549 & 1525 \\
\hline \multicolumn{11}{|l|}{ Aceites y grasas de origen animal } \\
\hline y vegetal, elaborados y ceras & 25 & 26 & 32 & 32 & 33 & 43 & 80 & 77 & 70 & 74 \\
\hline Alimentos para animales & 2983 & 2676 & 2195 & 2604 & 2911 & 4218 & 4258 & 3443 & 3360 & 3915 \\
\hline Exportaciones forestales & 1042 & 1199 & 989 & 1181 & 1526 & 2073 & 2267 & 2087 & 2087 & 2653 \\
\hline Primarias (corcho y madera) & 304 & 300 & 258 & 303 & 451 & 591 & 677 & 761 & 817 & 887 \\
\hline Secundarias & 738 & 899 & 731 & 878 & 1075 & 1482 & 1590 & 1327 & 1270 & 1766 \\
\hline Exportaciones pesqueras & 1103 & 1185 & 1318 & 1504 & 1861 & 1866 & 1900 & 1963 & 2495 & 2688 \\
\hline \multirow{2}{*}{\multicolumn{11}{|c|}{$\begin{array}{l}\text { Pescado fresco, refrigerado o congelado } \\
\text { Pescado seco, salado o en salmuera; }\end{array}$}} \\
\hline & & & & & & & & & & \\
\hline pescado ahumado & 11 & 10 & 15 & 14 & 15 & 23 & 29 & 28 & 40 & 65 \\
\hline $\begin{array}{l}\text { Crustáceos frescos, refrigerados, } \\
\text { congelados, salados, etc. }\end{array}$ & 798 & 892 & 847 & 954 & 1132 & 1117 & 1027 & 891 & 1137 & 1214 \\
\hline $\begin{array}{l}\text { Pescados, crustáceos y moluscos, } \\
\text { preparados o en conserva }\end{array}$ & 59 & 71 & 93 & 122 & 182 & 173 & 196 & 216 & 266 & 321 \\
\hline Exportaciones agrícolas totales & 22433 & 25040 & 23836 & 23688 & 22822 & 27375 & 27800 & 29516 & 29844 & 32286 \\
\hline Exportaciones totales & 78110 & 87039 & 84892 & 70237 & 77842 & 89859 & 100802 & 104196 & 107619 & 112336 \\
\hline
\end{tabular}

B. Participación en las exportaciones agrícolas totales, por categoría de productos (\%)

\begin{tabular}{|c|c|c|c|c|c|c|c|c|c|c|}
\hline Exportaciones de cultivos & 61.3 & 64.7 & 65.2 & 64,8 & 58.4 & 55.6 & 54.9 & 58.5 & 57.6 & 56.6 \\
\hline Frutas frescas o secas & 3.4 & 3.3 & 4.5 & 5.0 & 5.8 & 5.5 & 5.9 & 6.8 & 9.1 & 8.5 \\
\hline Nueces comestibles, frescas o secas & 0.5 & 0.4 & 0.7 & 0.7 & 0.6 & 0.6 & 0.6 & 0.7 & 0.6 & 0.8 \\
\hline Legumbres frescas o refrigeradas & 1.9 & 2.3 & 2.2 & 3.6 & 2.6 & 2.5 & 2.3 & 4.1 & 3.7 & 5.5 \\
\hline Cereales y preparados de cereales & 14.1 & 10.0 & 10.4 & 5.9 & 3.9 & 4.2 & 5.0 & 6.0 & 5.0 & 6.1 \\
\hline Café, té, cacao, especias y sus preparados & 23.6 & 26.0 & 27.6 & 32.6 & 24.9 & 20.3 & 17.6 & 13.7 & 13.7 & 10.7 \\
\hline
\end{tabular}


B. Participación en las exportaciones agrícolas totales, por categoría de productos (\%)

\begin{tabular}{|c|c|c|c|c|c|c|c|c|c|c|}
\hline & & & & & & & & & & \\
\hline & 1983 & 1984 & 1985 & 1986 & 1987 & 1988 & 1989 & 1990 & 1991 & 1992 \\
\hline Azúcar, preparados de azúcar y miel & 4.3 & 3.6 & 2.5 & 3.0 & 2.9 & 3.1 & 2.8 & 3.6 & 3.1 & 3.3 \\
\hline Algodón & 1.9 & 2.0 & 1.9 & 1.0 & 1.8 & 2.1 & 2.6 & 2.6 & 2.8 & 1.3 \\
\hline Semillas y frutos oleaginosos & 3.5 & 6.3 & 6.9 & 4.2 & 4.7 & 5.7 & 6.5 & 7.1 & 5.9 & 5.6 \\
\hline Productos vegetales en bruto & 0.9 & 0.9 & 1.0 & 1.1 & 1.2 & 1.3 & 1.4 & 1.5 & 1.8 & 2.0 \\
\hline Legumbres y frutas procesadas & 3.8 & 6.9 & 4.3 & 4.3 & 5.7 & 6.2 & 6.0 & 7.7 & 5.9 & 6.4 \\
\hline Legumbres procesadas & 0.4 & 0.4 & 0.4 & 0.5 & 0.7 & 0.6 & 1.0 & 1.0 & 1.0 & 1.0 \\
\hline Frutas procesadas & 0.2 & 0.3 & 0.2 & 0.3 & 0.5 & 0.4 & 0.5 & 0.6 & 0.7 & 0.8 \\
\hline Otras frutas y legumbres procesadas & 3.2 & 6.2 & 3.6 & 3.5 & 4.6 & 5.1 & 4.5 & 6.1 & 4.2 & 4.5 \\
\hline Bebidas y tabaco & 3.1 & 2.9 & 3.2 & 3.2 & 3.8 & 3.7 & 3.9 & 4.3 & 5.6 & 5.9 \\
\hline Productos y preparados comestibles diversos & 0.3 & 0.2 & 0.2 & 0.3 & 0.4 & 0.4 & 0.3 & 0.3 & 0.4 & 0.5 \\
\hline Exportaciones pecuarias & 10.6 & 7.7 & 7.9 & 8.8 & 9.5 & 9.4 & 9.5 & 10.3 & 10.2 & 9.7 \\
\hline Animales vivos, principalmente para alimentación & 1.0 & 0.5 & 0.8 & 1.2 & 0.9 & 0.8 & 1.0 & 1.5 & 1.5 & 1.3 \\
\hline Carnes y preparados de carne & 7.8 & 5.8 & 5.7 & 5.9 & 6.8 & 6.6 & 6.4 & 6.8 & 7.3 & 7.2 \\
\hline Productos lácteos y huevos de ave & 0.4 & 0.2 & 0.2 & 0.3 & 0.3 & 0.4 & 0.7 & 0.7 & 0.5 & 0.4 \\
\hline Lana y otros pelos de animales (excepto tops) & 1.3 & 1.1 & 1.0 & 1.1 & 1.3 & 1.4 & 1.1 & 1,1 & 0.6 & 0.6 \\
\hline Productos animales en bruto & 0.2 & 0.1 & 0.2 & 0.2 & 0.2 & 0.2 & 0.3 & 0.2 & 0.2 & 0.3 \\
\hline \multicolumn{11}{|l|}{ Exportaciones de aceites, grasas, harinas } \\
\hline y ceras, animal y vegetal & 18.5 & 18.1 & 17.1 & 15.1 & 17.2 & 20.6 & 20.7 & 17.5 & 16.8 & 17.2 \\
\hline Aceites y grasas de origen animal & 0.1 & 0.2 & 0.2 & 0.1 & 0.1 & 0.2 & 0.1 & 0.1 & 0.1 & 0.1 \\
\hline Aceites y grasas fijos de origen vegetal & 5.0 & 7.1 & 7.6 & 3.8 & 4.2 & 4.9 & 4.9 & 5.5 & 5.2 & 4.7 \\
\hline $\begin{array}{l}\text { Aceites y grasas de origen animal y vegetal, } \\
\text { elaborados y ceras }\end{array}$ & & & & & & & 3 & & 2 & 0.2 \\
\hline Alimentos para animales & 13.3 & 10.7 & 9.2 & 11.0 & 12.8 & 15.4 & 15.3 & 11.7 & 11.3 & $\begin{array}{r}0.2 \\
12.1\end{array}$ \\
\hline Exportaciones forestales & 4.6 & 4.8 & 4.1 & 5.0 & 6.7 & 7.6 & 8.2 & 7.1 & 7.0 & 8.2 \\
\hline Primarias (corcho y madera) & 1.4 & 1.2 & 1.1 & 1.3 & 2.0 & 2.2 & 2.4 & 2.6 & 2.7 & 2.7 \\
\hline Secundarias & 3.3 & 3.6 & 3.1 & 3.7 & 4.7 & 5.4 & 5.7 & 4.5 & 4.3 & 5.5 \\
\hline Exportaciones pesqueras & 4.9 & 4.7 & 5.5 & 6.3 & 8. & 6.8 & 6.8 & 6.7 & 8.4 & 8.3 \\
\hline Pescado fresco, refrigerado o congelado & 1.0 & 0.8 & 1.5 & 1.7 & 2.3 & 2.0 & 2.3 & 2.8 & 3.5 & 3.4 \\
\hline $\begin{array}{l}\text { Pescado seco, salado o en salmuera; pescado } \\
\text { ahumado }\end{array}$ & - & - & 0.1 & 0.1 & 0.1 & 0.1 & 0.1 & 0.1 & 0.1 & 0.2 \\
\hline $\begin{array}{l}\text { Crustáceos frescos, refrigerados, } \\
\text { congelados, salados, etc. }\end{array}$ & 3.6 & 3.6 & 3.6 & 4.0 & 5.0 & 4.1 & 3.7 & 3.0 & 3.8 & 3.8 \\
\hline $\begin{array}{l}\text { Pescados, crustáceos y moluscos, } \\
\text { preparados o en conserva }\end{array}$ & 0.3 & 0.3 & 0.4 & 0.5 & 0.8 & 0.6 & 0.7 & 0.7 & 0.9 & 1.0 \\
\hline Exportaciones agrícolas totales & 100.0 & 100.0 & 100.0 & 100.0 & 100.0 & 100.0 & 100.0 & 100.0 & 100.0 & 100.0 \\
\hline
\end{tabular}

Fuente: CEPAL, Unidad de Desarrollo Agrícola, a partir de datos del Banco de Datos del Comercio Exterior de América Latina y el Caribe (BADECEL), de la CEPAL.

a Argentina, Bolivia, Brasil, Colombia, Chile, Ecuador, México, Paraguay, Uruguay y Venezuela. 
América Latina (10 paises): a Exportaciones agrícolas tradicionales, 1983-1992

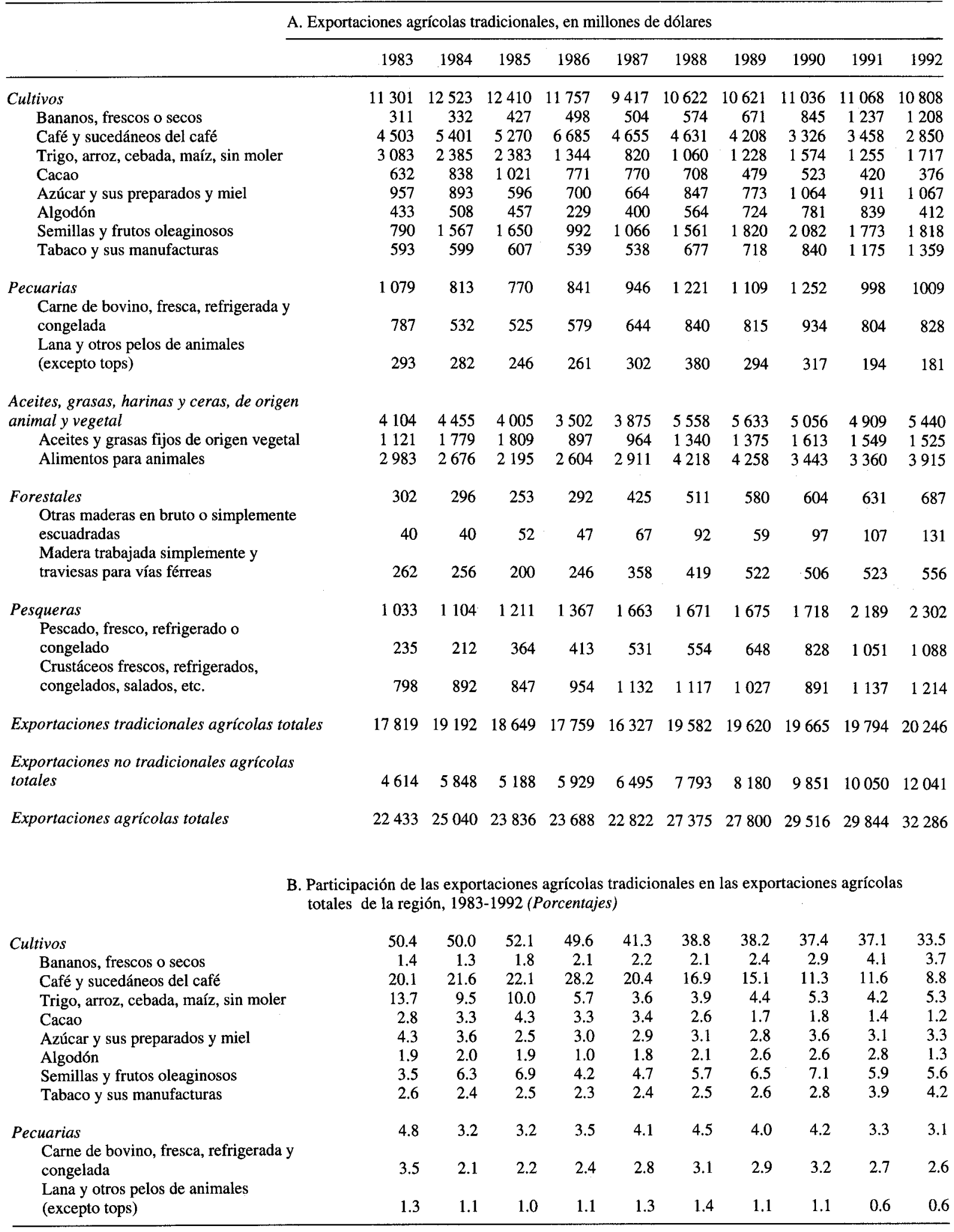


B. Participación de las exportaciones agrícolas tradicionales en las exportaciones agrícolas totales de la región, 1983-1992 (Porcentajes)

\begin{tabular}{|c|c|c|c|c|c|c|c|c|c|c|}
\hline & \\
\hline & 1983 & 1984 & 1985 & 1986 & 1987 & 1988 & 1989 & 1990 & 1991 & 1992 \\
\hline \multicolumn{11}{|l|}{ Aceites, grasas, harinas y ceras, de origen } \\
\hline Aceites y grasas fijos de origen vegetal & 5.0 & 7.1 & 7.6 & 3.8 & 4.2 & 4.9 & 4.9 & 5.5 & 5.2 & 4.7 \\
\hline Alimentos para animales & 13.3 & 10.7 & 9.2 & 11.0 & 12.8 & 15.4 & 15.3 & 11.7 & 11.3 & 12.1 \\
\hline & 1.3 & 1.2 & 1.1 & 1.2 & 1.9 & 1.9 & 2.1 & 2.0 & 2.1 & 2.1 \\
\hline $\begin{array}{l}\text { Otras maderas en bruto o simplemente } \\
\text { escuadradas }\end{array}$ & 0.2 & 0.2 & 0.2 & 0.2 & 0.3 & 0.3 & 0.2 & 0.3 & 0.4 & 0.4 \\
\hline $\begin{array}{l}\text { Madera trabajada simplemente y } \\
\text { traviesas para vías férreas }\end{array}$ & 1.2 & 1.0 & 0.8 & 1.0 & 1.6 & 1.5 & 1.9 & 1.7 & 1.8 & 1.7 \\
\hline \multirow{3}{*}{$\begin{array}{l}\text { Pesqueras } \\
\text { Pescado, fresco, refrigerado o } \\
\text { congelado } \\
\text { Crustáceos frescos, refrigerados, } \\
\text { congelados, salados, etc. }\end{array}$} & 4.6 & 4.4 & 5.1 & 5.8 & 7.3 & 6.1 & 6.0 & 5.8 & 7.3 & 7.1 \\
\hline & 1.0 & 0.8 & 1.5 & 1.7 & 2.3 & 2.0 & 2.3 & 2.8 & 3.5 & 3.4 \\
\hline & 3.6 & 3.6 & 3.6 & 4.0 & 5.0 & 4.1 & 3.7 & 3.0 & 3.8 & 3.8 \\
\hline Exportaciones tradicionales agrícolas totales & 79.4 & 76.6 & 78.2 & 75.0 & 71.5 & 71.5 & 70.6 & 66.6 & 66.3 & 62.7 \\
\hline Exportaciones no tradicionales agrícolas totales & 20.6 & 23.4 & 21.8 & 25.0 & 28.5 & 28.5 & 29.4 & 33.4 & 33.7 & 37.3 \\
\hline Exportaciones agricolas totales & 100.0 & 100.0 & 100.0 & 100.0 & 100.0 & 100.0 & 100.0 & 100.0 & 100.0 & 100.0 \\
\hline
\end{tabular}

